\section{RESOLVING CONFLICTS BETWEEN GREEN TECHNOLOGY TRANSFER AND INTELLECTUAL PROPERTY LAW}

\section{Robert Percival and Alan Miller}

Global climate change represents the most difficult environmental challenge facing the world today. The struggle to reach consensus on a global policy for responding to it has exposed sharp divisions between developed countries and the developing world. There is wide recognition that a global transformation toward a green energy infrastructure is necessary and perhaps even essential; analyses by the International Energy Agency conclude that keeping atmospheric carbon dioxide within environmentally necessary levels requires a technology "revolution." However, there is considerable uncertainty over the best means for bringing this about. Although technological innovation can play an important role in reducing greenhouse gas emissions, developing countries fear that principles of intellectual property law will hinder the transfer of green energy innovations to them.

The recent decisions at COP 16 in Cancun produced some agreements on technology issues without resolving some underlying tensions. The parties agreed to establish a technology mechanism including a technology executive committee (TEC) and a Climate Technology Centre and Network (CTCN). The TEC was given a broad mandate to promote transfer of technology for climate mitigation and adaptation including analysis of technology needs, barriers, and policy issues. The CTCN provides a potential means of advancing these objectives via a network of organizations with the capacity to provide advice and support technology transfer activities, including identifying and promoting best practices, building local institutional capacity, and reaching out to public and private stakeholders. Developing countries had sought to include intellectual property supporting technology innovation and transfer, but this was opposed by industrialized countries and excluded. In the waning hours of the Cancun negotiations, Bolivia noted the dominant ownership of clean technology patents by industrialized countries in stating its opposition to the final agreement (see table, Clean Technology Patents by Country). The importance of intellectual property for achieving the goals of the climate convention therefore remains a contentious issue and high on the agenda for many parties, although currently outside the technology mechanism created in Cancun.

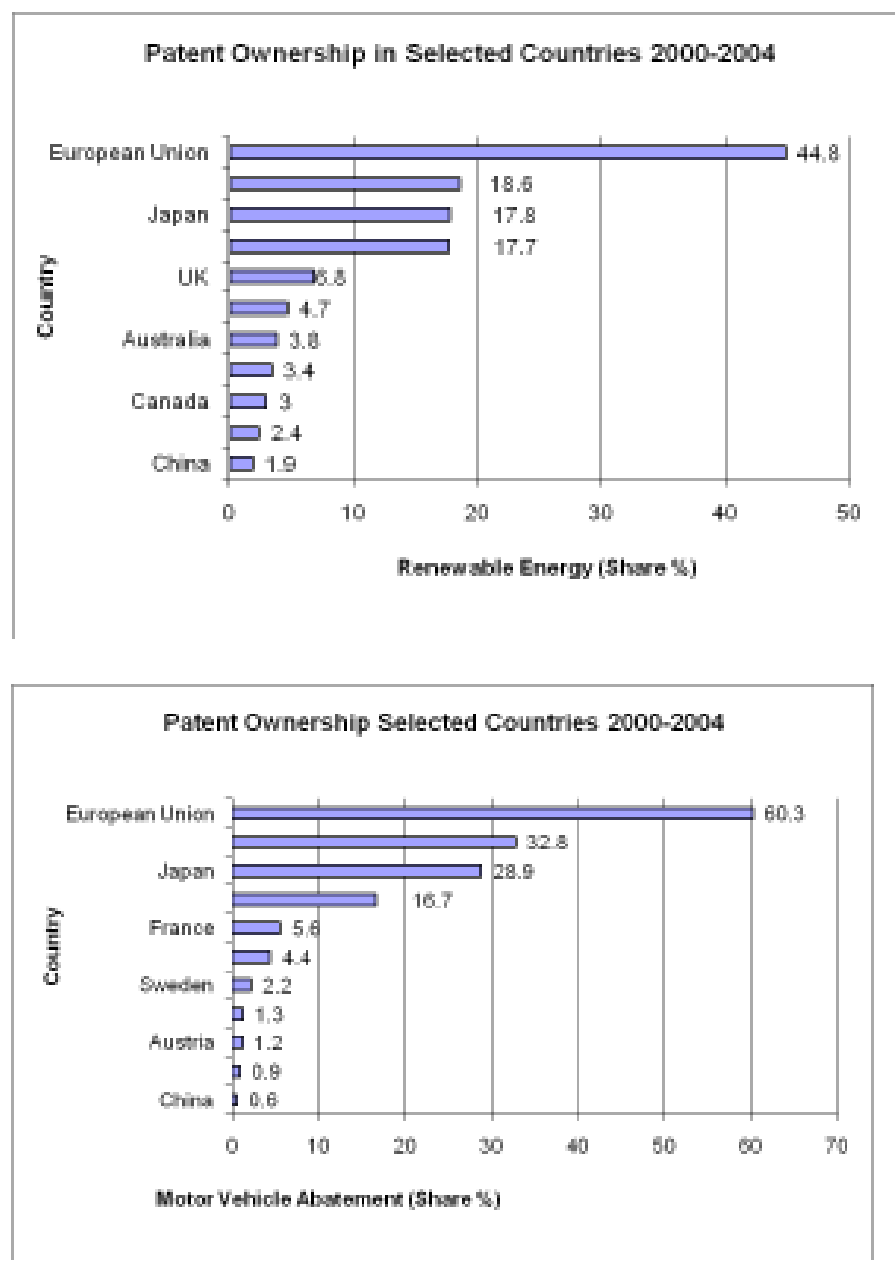

The green technology transfer debate has centered on the possibility of relaxing intellectual property rights (IPRs) to facilitate the transfer of technologies from developed to developing countries that would not otherwise be able to afford them. Arguments in favor of relaxing IPRs generally stress that the ability of national governments to use strategies such as compulsory licensing is justified by a compelling public "health" or "emergency" interest. Opponents generally maintain that relaxing IPRs will discourage innovation by reducing potential financial rewards, particularly with respect to very dynamic markets like the global renewable energy technology market at a time when a growing number of countries (including developing nations) are implementing various initiatives to facilitate 
and encourage renewable energy research and development.

Until recently, technology transfer has been left to the dynamic of international market forces and the business decisions of transnational corporations. These forces placed a premium on IPR protection and created "supply-side restrictions" and "demand-side limitations" that in turn were perceived to create obstacles to otherwise economically and environmentally valuable transfers of technology. Elizabeth Burleson, Energy Policy, Intellectual Property, and Technology Transfer to Address Climate Change, 18 Transnat'L L. \& Contemp. PROBs. 69, 86 (2009). Recently, international institutions have begun to establish frameworks to facilitate the transfer of green technology from developed countries to developing countries, responding to ideas promoted in the convention negotiations and anticipating the need for new initiatives in preparation for the 2012 expiration of the Kyoto Protocol. Mei Gechlik, Making Transfer of Clean Technology Work: Lessons of the Clean Development Mechanism, 11 San Diego InT'L L.J. 227, 228 (2009).

In December of 2008 the climate change negotiations in Bali produced a draft technology transfer agreement that enumerated certain goals for future progress, “including technology needs assessment, joint R\&D programs, a healthy technology transfer environment, and licenses.” Michael Hasper, Green Technology in Developing Countries: Creating Accessibility Through a Global Exchange Forum, 2009 DukE L. \& TeCH. Rev. 1 (Jan. 15, 2009). The United States and the European Union had hoped to eliminate tariffs on climate change mitigation techniques to facilitate the flow of ideas into developing countries, but developing countries were skeptical that the proposal was merely “disguised protectionism” to boost exports. The parties also clashed over whether to relax IPRs to facilitate the smooth flow of technology consistent with the argument that developing countries must "leapfrog" over dirty technologies to a new generation of clean alternatives.
To facilitate developing country leapfrogging, Hasper recommends tapping into the market for green technology in developing countries through the use of a global technology exchange forum that brings technology holders, venture capitalists, and domestic entrepreneurs together to reduce information asymmetries and transaction costs. He also urges that those participating in the developing country green technology markets not neglect the role of indigenous firms better aware of local needs and thus better positioned to implement technologies that meet local needs. Perhaps explicitly incorporating this awareness into technology transfer plans and programs such as those to be implemented by the Cancun Agreements will ease developing countries' concerns that developed countries are only interested in reducing climate change technology tariffs to increase exports. (Ironically the United States has recently found itself on the other side of this issue, complaining to the World Trade Organization about Chinese subsidies for export of wind machines and restricting defense procurement of imported renewable energy equipment.)

There is a growing interest in creating a global technology exchange forum that follows the opensource operating system model; a sort of "Wikipedia" of green technology exchange. Jerome H. Reichman, Intellectual Property in International Perspective: Institute for Intellectual Property \& Information Law Symposium, 46 Hous. L. REV. 1115, 1147-48 (2009). One global exchange scheme already in operation is the Eco-Patent Commons. Companies have offered a number of patents with environmental benefits free of charge through the Eco-Patent Commons with one limitation: defensive termination. If a non-pledger attempts to assert a patent against a pledger, the pledger has the option to defensively terminate its non-assert agreement (i.e., agreement not to sue). Since launching in 2008, the Eco-Patent Commons has received approximately 100 ecofriendly patent pledges. This year, Green Xchange will start a partnership with Creative Commons and will provide eco-friendly patents for fixed annual licensing fees. Voluntary patent-sharing forums such as EcoCommons and Green Xchange are praised as alternatives to making substantive changes to the law, which means these forums are inherently a faster means 
of exchanging green technology. Estelle Derclaye, Not Only Innovation but also Collaboration, Funding, Goodwill and Commitment: Which Role for Patent Laws in Post-Copenhagen Climate Change Action, 9 J. Marshall Rev. Intell. Prop. L. (Special Issue) 657 (2010). More such efforts might be promoted by the technology mechanism.

Asignificant portion of recent literature on technology transfer to developing countries has focused on resisting substantive changes to the law on the grounds that IPR protection spurs innovation and is essential for attracting foreign direct investment. However, other studies suggest that stronger IPRs are not necessary and may in fact hinder green technology transfer. Reichman has suggested that developing countries can accommodate developed countries' standards for patent protections in a way that better facilitates technology transfer by "adopting relatively stringent eligibility standards covering subject matter, novelty, nonobviousness, and disclosure.” India has aggressively pursued this strategy to meet development goals in its pharmaceutical industry, establishing a strict nonobviousness standard that requires "a technical advance” or economic significance. Recently passed Chinese patent law adopts a broader, more absolute novelty standard and also requires disclosure of origin for genetic resources. The United States has also recently begun to tighten its patent eligibility standards, though not as much as India.

The ratification in 1995 of the Agreement on TradeRelated Aspects of Intellectual Property Rights (TRIPS) first introduced intellectual property law into international trade. The agreement applies to all members of the World Trade Organization (WTO); developing country members were granted a grace period of a decade to comply. In 2001, WTO members in Doha adopted a declaration entitled "Declaration on the TRIPS Agreement and Public Health" in response to growing concerns that IPRs could restrict access to affordable medicines for populations in developing countries in their efforts to control diseases of public health importance, such as HIV, tuberculosis, and malaria. The declaration recognizes concerns about adverse effects of IPRs on prices to consumers and sets out conditions under which a government can license a third party without the consent of the patent holder. The Doha declaration also extended the grace period for compliance with TRIPS to January 2016 for least developed countries (WHO 2010).

Another method for circumventing strong IPR protections is to allow compulsory licensing and related measures. Compulsory licensing is permitted under TRIPS in times of "emergency" and has generally been used for pharmaceutical products used to fight epidemics such as HIV/AIDS. Recent use of compulsory licensing has expanded the scope of its application to include pharmaceuticals used to treat long-term health problems such as heart disease and cancer. Robert Fair, Does Climate Change Justify Compulsory Licensing of Green Technology?, 6 B.Y.U. Int'L L. \& Mgmt. Rev. 21, 24 (2009). Some argue that climate change is a long-term health problem or that it is an "emergency," thus justifying the use of compulsory licensing to increase access to green technology.

An example of effective use of compulsory licensing was the 2005 action by Brazil to break HIV/AIDS pharmaceutical patents owned by Abbott Laboratories by suspending the patents and authorizing the production of generic versions of the drugs. This saved Brazil \$250 million when Abbott responded by lowering the price it had charged for its antiretroviral drugs. Similarly, Thailand approved compulsory licensing for an AIDS drug in 2007 after failing in negotiations to reduce the cost of the drugs. The WTO upheld these exceptions as legitimate under Article 30 of the TRIPS agreement. Many European countries have codified compulsory licensing provisions into patent laws that are compatible with the TRIPS agreement, though until recently patent authorities were reluctant to grant compulsory licenses despite these provisions. German intellectual property law permits the most controversial TRIPS flexibility: compulsory licenses in the interest of public welfare. Nevertheless, Germany continues as a leader of green technology and apparently has yet to exercise the power of compulsory licensing in the green technology sector. 
The use of compulsory licenses has generally been reserved to the pharmaceutical industry and countries have taken other intellectual property avenues to promote green technology transfer. Professor Derclaye suggests several IPR incentives that could be used to promote green technology, including "accelerated examination, reduction, cancellation or waiver fees, removal of green inventions from deferred examination, earlier publication and/or priority at the opposition and infringement stages, [and] stronger protection.” One example is the United Kingdom's Intellectual Property Office fast track system for green technology, also referred to as the “Green Channel.” As of May 12, 2009, patent applications for green technologies can take advantage of an accelerated procedure in which the applicant simply makes a request in writing making "a reasonable assertion that the invention in the patent application is one which has some environmental benefit," and "which actions [he/she] wish[es] to accelerate: Search, Combined Search and Examination, Publication, and/or Examination.” The U.S. Patent and Trademark Office introduced a similar system in December of 2009. Expansion and Extension of the Green Technology Pilot Program,75 Fed. Reg. 69,049-50 (Nov. 10, 2010) (Dec. 8, 2009). Australia and South Korea have also launched similar programs and China, Japan, and Brazil have expressed interest in following suit. Thus, although international institutions and nations have yet to strike IPRs with a heavy blow in the interest of green technology transfer, it seems as though some countries are slowly moving toward more fluid movement of green technology by making minor yet significant adjustments to patent procedures. Maskus and Okediji question whether approaches relying primarily on the threat of compulsory licensing can be very effective. "[N]on-voluntary mechanisms tend to discourage the efficacy of any technology gained thereby, particularly where associated data and know-how are integral to the use or adaptation" of the technology. They advocate a mix of financial inducements and more streamlined systems of licensing to create a range of options. Maskus \& Okediji, Intellectual Property Rights and International Technology Transfer to Address Climate Change: Risks, Opportunities and Policy Options (International Centre for Trade and Development, 2010). Bilateral and multilateral environmental agreements can create a climate for technology cooperation such that otherwise patentable knowledge is freely shared. For example, the United States and China recently agreed to the creation of a Joint Clean Energy Research Center, with a commitment of \$150 million over five years shared evenly between the two countries. The Montreal Protocol experience also provides numerous examples of international collaboration to share environmental technology in the context of phasing out ozonedepleting chemicals. In several instances expert teams were formed to solve common technical problems arising from the phaseout, often bringing together technical staff from private firms competing in the market. Stephen O. Andersen, K. Madhava Sarma \& Kristen N. Taddonio, Technology Transfer for the Ozone Layer: Lessons for Climate Change (2007).

\section{Conclusion}

This paper examines claims that intellectual property law, which is designed to create incentives for innovation, actually may inhibit the transfer to developing countries of green energy innovations. Although the paper cannot find significant examples of green energy technologies whose diffusion has been hindered by existing intellectual property protections, it explores strategies, such as compulsory licensing schemes, for responding to such problems if and when they arise in the future. The paper concludes that intellectual property law need not be an obstacle to a global transformation toward a green energy infrastructure that can promote economic development while advancing new levels of international cooperation.

Robert V. Percival is the Robert F. Stanton Professor of Law and the director of the Environmental Law Program at the University of Maryland School of Law.
Alan Miller is principal climate change specialist at the International Finance Corporation, the private sector arm of the World Bank Group, and co-editor of the newsletter. 